This document is published in:

British Journal of Educational Technology, Volume 44, issue 4 (July 2013), p. 616-628.

ISSN: 0007-1013 DOI: http://dx.doi.org/10.1111/bjet.12047

(C) 2013 British Educational Research Association. 


\title{
An Augmented Lecture Feedback System to support Learner and Teacher Communication
}

Telmo Zarraonandia, Ignacio Aedo, Paloma Díaz, Alvaro Montero

Telmo Zarraonandia, Departamento de Informática - Escuela Politécnica Superior, Universidad Carlos III de Madrid, Avda. de la Universidad, 30, 28911 Leganés - Madrid-Spain. Email: tzarraon@inf.uc3m

\begin{abstract}
In this paper it is advocated that the feedback loop between students and lecturer could be improved by making use of Augmented Reality (AR) techniques. The bidirectional communication teacher-students is sometimes hampered by students' fear of showing themselves up in front of their classmates. In order to overcome this problem a system is proposed whereby lecturers receive immediate and private feedback both individualised for each student as well as aggregated for the whole class. With that purpose the lecturer, who is equipped with a head mounted AR display, can visualize symbols that student select to represent their status in relation to the lecture content. In order to explore the possibilities of this approach an experience was conducted in a lecture on a university course. The results are encouraging and suggest that as this technology matures and less intrusive AR display models become available, it could provide effective support to communication and interaction during lectures.
\end{abstract}

\section{Introduction}

The success of a lecture depends to a great extent on the ability of the lecturer to successfully communicate with the audience [Dubrow and Wilkinson, 1984]. This communication is not just a one-way flow from the lecturer to the students since teachers need continuous feedback from students to be aware of whether they are grasping the concepts and of the adequacy of the lecture delivery pace. Unfortunately, in many cases students' fear of showing themselves up in front of their classmates hampers this communication. Many students are shy and feel reluctant to speak up their difficulties to follow the lecture and even they might fail to articulate them properly when the lecturer stops the presentation to ask for questions and clarifications. As a result, the lecturer has to infer students' knowledge and progress from their facial expressions and attitudes in many cases, a method that is absolutely subjective and can easily lead to misinterpretations. This scenario could be alleviated by making use of a Classroom Communication System (CCS). This type of system allows the lecturer to visualize diagrams depicting histograms of the answers that students send using special devices or clickers [Caldwell, 2007]. However, CCS stops the normal flow of the lesson to allow the lecturer to visualize the results gathered. Furthermore, as the answers are collected 
anonymously, the lecturer is unable to identify which students are experiencing troubles in understanding the concepts. In fact, the focus of CSS is the promotion of active learning and participation of the student [Durfresne et al., 1996] rather than providing the lecturer with continuous feedback on their status and acquired knowledge.

In [Zarraonandia et al, 2011] the architecture of a system which made use of Augmented Reality (AR) techniques to improve the communication among the participants of a lecture was presented. AR techniques have been successfully used for enhancing interaction of the learners with the learning content [Chen and Chao, 2008; Shelton and Hedley, 2002], but little attention has been given to its use for supporting the lecturer's tasks [Cooperstock, 2001]. This way, the basic idea behind the proposed system was to allow students to display visual cues that would depict their current status, and that only the lecturer would be able to see through an AR device. Students would then be provided with a communication channel hitherto unavailable to them that would allow them to communicate with the lecturer in a private and immediate way, without fellow students even noticing and without interrupting the lecture. This paper constitutes a further development of this idea by presenting an Augmented Lecture Feedback system (ALFs) developed in accordance with that architecture, and an evaluation experience conducted during a lecture on a university course. In the experience, the lecturer made use of a head mounted AR display to visualize students' clues and notes on the presentation. The results of these experiments are discussed at the end of the paper.

\section{ALF system}

Figure 1 depicts an augmented lecture supported by the ALF system. As depicted in the figure, students interact with ALFs using their mobile devices, while the lecturer controls both system and presentation software through movements captured by a Microsoft Kinect camera. The ALF system processes this information together with the video captured by the lecturer's AR device, and augments lecturer's vision accordingly with representations of the students' states and notes on the current lecturer activity.

Figure 1 here 


\subsection{System Architecture and Implementation}

As shown in figure 2, the system architecture considers three different layers: knowledge modelling, communication and representation. The knowledge modelling layer supports the lecturer in describing the lecture plan and the information she aims to elicit from the students during the lecture through the Lecture Authoring tool (section 2.1.1). The communication layer provides students with the means to communicate with the lecturer through the Lecture Player module (section 2.1.2). Finally, the representation layer allows the lecturer to visualize AR representations of the feedback provided by the students by means of the Visualization and Identification system (section 2.1.3). There is forth a module, the Natural Control system, that facilitates the lecturer controlling all the system functionalities and managing the presentation. These four modules are described in this section.

Figure 2 here

\subsubsection{Lecture Authoring Tool}

The Lecture Authoring tool facilitates lecturers the description of lecture plans. A lecture plan outlines the sequence of activities to be carried out during a lecture, and it also describes the type of the feedback the lecturer needs from the audience. During the lecture this feedback can be used to support the communication between students and lecturer, and once the lecture has finished it can also be used as a log of what happened during the lecture to identify and improve activities in which students experienced problems. Figure 3 depicts the model used by the tool to describe such plans. As shown in the figure, each Activity is associated with at least one Concept to be taught and a learning Objective to be attained. Activities are the points in the lecture that make it possible to receive feedback from students. With that purpose the lecturer can provide a set of status or range of values to be used by the students to describe their Comprehension Level on the activity, such as "I don't understand it", "It's perfectly clear" or "I have some doubts". An Activity can be classified as a Lecturer Activity or a Student Activity according to the role played by the student in it. An archetypical example of Lecturer Activity is an explanation of a concept primarily performed by the teacher whilst a question round, exercises and discussions chiefly led by students are classified as Students Activities. For these latter activities, the lecturer can also provide a second set of values that students can used to describe their current state, such as "Just started the exercise", "Already 
finished", "I know the answer" or "I don't know how to get to the answer".

Figure 3 here

\subsubsection{Lecture Player}

The communication between the participants of a lecture is supported by a web application called "Lecture Player". Before the lecture starts the teacher upload a lecture plan to the player, making it available to the group of students. The player provides two different views, one for the lecturer and one for the students (Fig 4), the last one optimized for its access through mobile devices. As the lecturer progresses through the lecture, she can use the lecturer's view to select from the previously specified sequence of activities the one which is about to start. The students' view of the system is then updated so they can start updating their current status and comprehension levels for that specific activity. This information is stored in player's database so the representation layer of the system can retrieve it.

Figure 4 here

\subsubsection{Visualization and Identification Module}

The visualization and identification module implements the functionalities related to the representation layer of the system. The module processes the video signal captured by the AR device, try to identify students in the image and when succeed generates a video output containing 3D images of symbols that represent the current status of the student in the lecture player database. The matching between symbols and statuses should be carried out by the lecturer on beforehand. These images are generated at a position and size in the screen calculated based on the coordinates and estimated distances of the students in the input video. This way, when they are displayed on the AR device overlapping the real vision of the lecturer, she has the impression that symbols appear over the corresponding student's head. In addition the application also displays a pie chart depicting the distributions of students responses, the name of the activity in course, and it provides support to the presentation by allowing displaying notes on the activities previously introduced in the authoring tool. 
The module has been implemented making use of the Windows Presentation Foundation for the generation of the output images, which at present can be crosses, ticks and question marks. The latter two are available in different colours to facilitate depicting a wide range of knowledge grades and statuses. The artificial vision library EmguCV has been used for supporting the identification of the students, which at this moment can be based on markers, facial recognition and a combination of markers and classroom positions. The latter method was specially implemented for the experience described in this paper as some students were too far away from the lecturer. To solve the problem the application will consider that each student will be placed in a fixed position in the classroom, which could be calculated taken as a reference the positions of two makers placed on the first row of seats. The model of AR device used is a pair of Vuzix Wrap 920 AR eyewear.

\subsubsection{Natural Lecture Control Module}

Having to control all the system functionalities while at the same time carrying out a speech and managing the presentation software might increase the complexity of the lecturing task. In order to provide a seamless integration of the control of these functionalities in the lecture, ALFs includes the Natural Lecture Control (NLC) module. The module allows the lecturer to map the activation of the functionalities of the identification and visualization module and the lecture player by means of a set of pre-defined physical gestures, such as swiping a hand, raising it or pushing it. In addition, the module also provides support for managing the presentation software allowing the lecturer to navigate to the next or previous slide using gestures. The module makes use of a Microsoft Kinect camera and has been implemented using the Kinect Software Development Kit.

\subsection{Experiment Description}

In order to explore the benefits that the ALF system may report we carried out an experience during a lecture on the Computer Technologies for the Web course of the Computer Engineering degree at University of Carlos III of Madrid. ALF was used to support one of the lectures on the course, and both the students and lecturer who collaborated in the experience evaluated its different functionalities. It should be pointed out that the research team were aware that the use of the lecturer's head mounted AR display would imply the introduction of an intrusive element into the lecture, which would possibly hinder the lecturer's movements 
and expressivity, and this could have a direct impact on the students' attitude. Bearing this limitation in mind, the focus of the experience was not set on assessing the usability of a system prototype that given the current technology has obvious drawbacks but on getting some insight into the lecture participants' reaction to the system. The goal was to identify strengthens and weakness of the proposed approach, and to distinguish between problems which could be resolved by using alternative or improved versions of the devices, and those which meant limitations of the approach.

A total of 11 students enrolled in the course and one of their teachers collaborated in the experience. Beforehand, the teacher had made use of the Lecture Authoring tool for defining the lecture plan depicted in Table 1. As shown in the table the lecture covered the specific subject of Java Server Pages Tag Libraries, and it included four different types of activities: expositions, question rounds, exercises and discussions. For the first one the lecturer specified 3 different knowledge levels and for the other ones different sets of values of status. In addition some notes to visualize during the lecture were also included. The lecture took place in a computer room, and before it started both students and lecturer were trained in the operation of the system by playing a lecture script similar to the one they were about to use. The training session took about $15^{\prime}$ and finished when all the participants confirmed they knew how to use all the system functionalities. At the end of the experience the lecturer was interviewed and students were asked to fill a questionnaire.

\section{Table 1 here}

\section{Experiment Results}

Fig 6 depicts some pictures taken during the augmented lecture showing the sight from the position of the students as well as the image of the class the lecturer obtained through the AR device. As shown in the pictures, the pie chart of the responses was depicted in the top right hand side of the AR display's screen, whereas the name of the current lecture activity and the notes appeared at the bottom. In general the lecture was carried successfully and was completed in the scheduled time without major obstacles. Next the responses collected from students and lecturer about the experience are analysed.

Figure 5a-b-c here 


\subsection{Students' perspective}

The results of the experience from the perspective of the students are summarized in Table 2 and figures $6 \mathrm{a}$ and $6 \mathrm{~b}$. The table shows the questions used to gather their opinions and the mean value and the standard deviation obtained for each of them, while the diagrams depict the distributions of the answers.

As shown in the table the questionnaire was divided in three sections. The first one aimed to get feedback on the overall experience of the students by asking them to rate their level of conformity with a set of statements using a five points Likert scale ranging from 1 (strongly disagree) to 5 (strongly agree). According to their answers students seemed to agree that the system could improve the interaction with the teacher and that it can even enhance engagement in the activities (Q3 and $\mathrm{Q} 4=4.00)$. Most of the students also agreed that in general the system can improve the communication with the lecturer. Answers to question Q5 are also encouraging, as they show that none of them seem to feel uncomfortable with the idea that the teacher will know their status during the whole lecture. Although responses to the question about willingness to use a similar system in the future (Q6) cannot be described as enthusiastic, they tend more to positives responses (6 students) than negatives ( 1 student) (Fig. 7).

The second section aimed to help to identify for which activities the system is considered more useful. According with the answers provided by the students using a five points Likert scale of level of usefulness from 1 (not useful at all) to 5 (very useful) they clearly perceived the system as useful for supporting question rounds. However, its utility for supporting the other activities is less clear, especially for the case of the discussions.

Finally, the last section of the survey included a set of open questions intended to providing comments, suggestions and further explanations about their experience. The comments obtained were mainly positive ("It is a very good idea", "A very interesting experience", "Good way to provide feedback to the lecturer") and emphasized the potential of the prototype. Their suggestions focused on providing a wider range of choices of status and knowledge levels, and on the use of computer terminals instead of mobile devices for supporting the communication.

Table 2 here

Figures $6 a-b$ here 


\subsection{Lecturer' perspective}

The overall lecturer's opinion of the system was clearly positive. He valued specially the support provided to the questions rounds and the explanations. With regards to the former he stated that "Most of the times it's quite hard to get a direct and quick answer from students on whether they remember something from previous lectures. I'm used to get at most some nods from which I have to infer if I should repeat previous explanations. This time looking at the symbols the student activated I clearly identified when those explanations were necessary and when I could skip them". In the same way, and with relation to the explanation he said: "It was really rewarding to see how students progressively set their symbols to 'ok, I understand' as I advanced through my explanation. Then I moved to the next slide, in which an implementation example was presented, and all their symbols went back to red. By the time I finished explaining the example most of them were again green although, as some of them still didn't change, I repeated some of the main points. Once I noticed those few changed to green I moved to the next slide". On the contrary, the usefulness of the system in the exercises and discussion activities were less evident. According to the lecturer this could be due the exercise proposed was a bit long, and once students started working on it they seem to forget updating their status in the application. With regards to the discussion, most of the students selected the most restrictive status to inform the lecturer they did not want to participate. At the end the students who took part in the debate were the ones who habitually participate.

Leaving aside the support for the feedback, the functionality most appreciated by the teacher was the possibility to display notes about the activities on the AR goggles: "Until now this always required to avert the gaze from the class to the laptop screen or the document". On the other side, the support for controlling the presentation and the system through natural gestures was the feature of the system less satisfactory. Although in general responded well, to avoid the system failing to recognize or to misinterpret a gesture the lecturer ended up doing exaggerated movements, which were "all but natural".

\section{Discussion}

Though the number of participants is quite limited as to derive general conclusions, the results 
of the experience are encouraging. Responses have been mainly positive both from the perspective of the students as well as from the lecturer, which is of great significance given the inherent difficulty of both having to deliver a lecture with an unwieldy device on the head, as well as to follow it. Communication and interaction among lecturer and students seemed to improve, although the most clear benefit the system reported was that it helps the lecturer to adapt the explanations and pace of the lecture to the current knowledge and status of the audience, in a way which was difficult to achieve until now. This suggests that the use of the system could help to improve the effectiveness of the lecture, as extra examples and explanations will only be delivered when needed. However, this is still subject to speculation, and it would need to be corroborated through an exhaustive evaluation.

On the other hand, the usefulness of the system for exercises and discussion has not been clearly stated. In the former case this could be related to the fact that the exercise proposed was quite long. Therefore, the pace of the lecture was broken and students could address the lecturer directly and in private, without requiring the use of the system to do it. It would be necessary then to carry out further investigation on the results obtained for shorter exercises and probably provide pedagogical clues about how to design this kind of experiences. Similarly, as the numbers of students who participated during the discussion was quite low, the potentiality of the system for supporting this type of activity might not have been fully exploited.

In any case, the experience described here is limited to the context of one single lecture with a reduced number of students. In order to confirm or dismiss the benefits previously mentioned it would be necessary to carry out further research in larger classes and during many lectures. Unfortunately, due the technical limitations of the current head-mounted AR devices models, it is difficult to organize those experiences at present. In addition, it is necessary to consider that both students and lecturer are all of a technical background, and that the responses from lecture's participants with other, less technical backgrounds, could be less positive.

\section{Conclusions and Future Work Lines}

The results of the experience are very promising. Even considering all the current technical limitations, the system succeeded in supporting the immediate and private gathering of feedback from students during a lecture, and the responses obtained from the participants were positive. It is very likely that as AR technology matures, most of those limitations will be overcome, allowing teachers to use non-intrusive head-mounted AR displays in their 
lectures. The use of this technology to support teacher activity in the classroom offers new and exciting possibilities, and has the potential to modify the traditional way in which they are carried out.

Current lines of research included the extension of the system to allow the lecturer to display background information about the student or information related to previous marks on the course. In addition, a new version of the system that does not make use of a knowledge modelling layer is also under development. Students will be offered a large set of choices among which they can freely choose the one that better describes their current status, regardless of the activity the lecturer is carrying out. Finally, other possibilities to facilitate control all the system functionalities in a way non intrusive and easy to remember are being explored. These include the use of game pads, which provide a wide range of controls, and the combination of activation of game pads with a small range of gestures.

\section{Acknowledgments}

This work is supported by the project TIPEx funded by the Spanish Ministry of Science and Innovation (TIN2010-19859-C03-01). The authors also would like to thanks the students Estefanía Fernández and Alejandro Serrano for helping with the implementation of the system, and the participants who collaborated in the experience described.

\section{References}

1. Dubrow, H. and Wilkinson, J. (1984). The theory and practice of lectures. In M. Gullette (Ed.), The art and craft of teaching, Cambridge, MA: Harvard University Press, pp. 25-37

2. Caldwell, J.E. (2007). Clickers in the large classroom: current research and best-practice tips. CBE Life Sciences Education, 6, pp. 9-20.

3. Chen, G-D and Chao, P-Y (2008), Augmenting Traditional Books with Context-Aware Learning Supports from Online Learning Communities, Journal of Educational Technology and Society, Volume 11, Issue 2, 27-40

4. Cooperstock, JR, (2001), The classroom of the future: enhancing education through augmented reality, In Proceedings of HCI International Conference on Human-Computer Interaction, 688-692

5. Durfresne R.J., Gerace, W.J., Leonard, W.J., Mestre, J.P. and Wenk L. (1996), Classtalk: A Classroom Communication System for Active Learning, Journal of Computing in Higher Education, Vol 7, No. 2, pp. 3 - 47

6. Shelton, B.E. and Hedley, N.R. (2002) Using augmented reality for teaching Earth-Sun relationships to undergraduate geography students, First IEEE Augmented Reality Toolkit International Workshop

7. Zarraonandia, T., Francese, R., Passero, I., Díaz, P. and Tortora, G (2011). Augmented Lectures around the corner?, British Journal of Educational Technology, Volume 42, Issue 4, E76-E78 


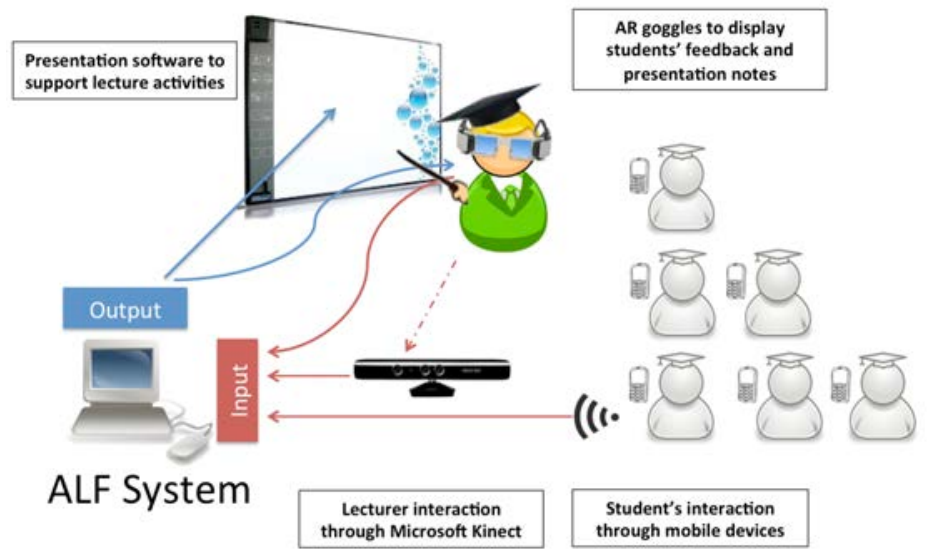

Figure 1: An augmented lecture supported by the ALF system 


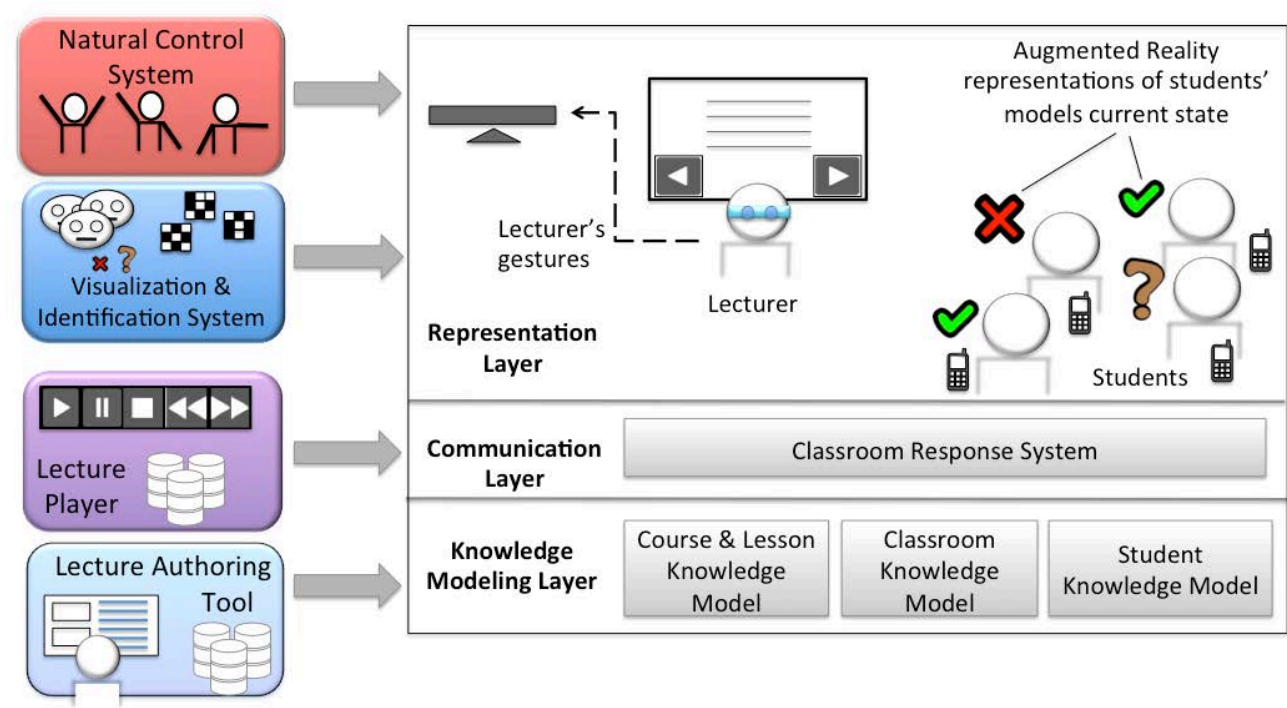

Lecture Designer

Figure 2: Architecture of the ALF system 


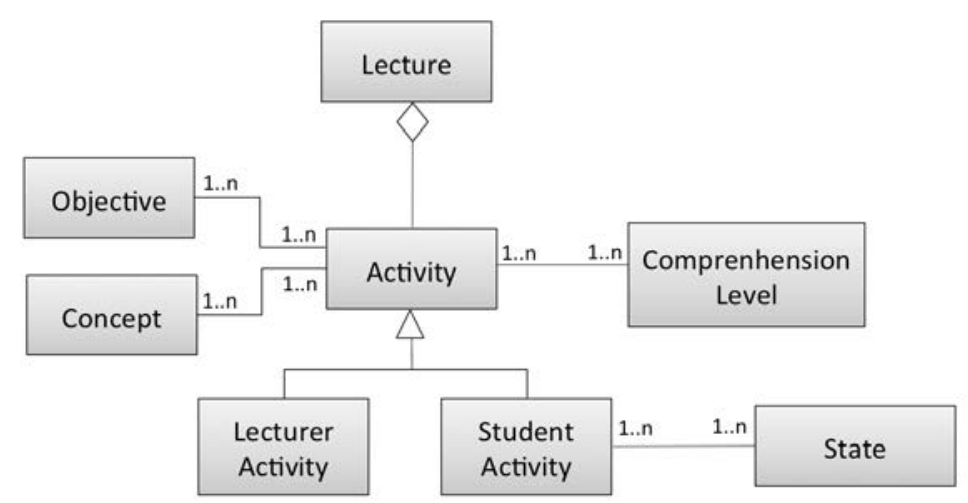

Figure 3: Model of the lecture plan 

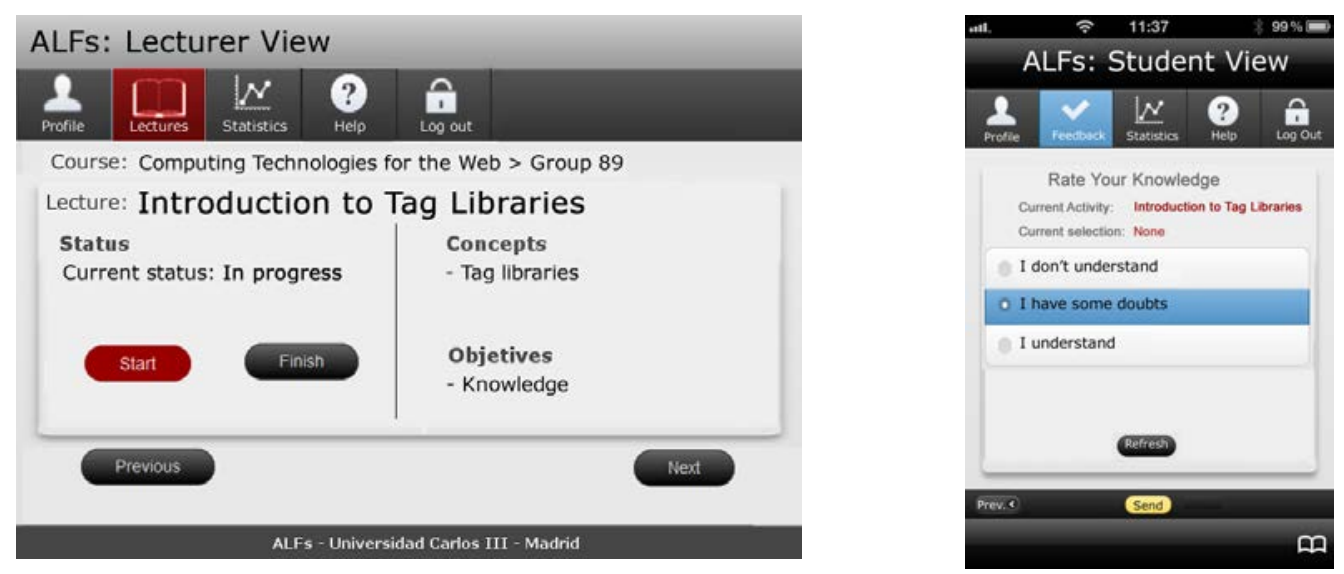

Figure 4: Lecturer's and student's view of the lecture player 
Table 1: Lecture plan used in the experience

\begin{tabular}{|c|c|c|c|c|c|c|}
\hline $\mathbf{N}^{\mathbf{o}}$ & $\begin{array}{l}\text { Activity } \\
\text { Type }\end{array}$ & Activity Description & Concept & Objective & $\begin{array}{c}\text { Student's Knowledge } \\
\text { States }\end{array}$ & Student's Status \\
\hline 1 & $\begin{array}{l}\text { Question } \\
\text { Round }\end{array}$ & $\begin{array}{l}\text { Ask students if they remember } \\
\text { Java Server Page's basic concepts }\end{array}$ & $\begin{array}{c}\text { Java Server } \\
\text { Pages }\end{array}$ & Knowledge & & $\begin{array}{l}\text { - I know the answer } \\
\text { - I don't know the answer } \\
\text { - I'm not sure }\end{array}$ \\
\hline 2 & Exposition & Introduction to Tag Libraries & $\begin{array}{l}\text { Tag } \\
\text { Libraries }\end{array}$ & Knowledge & $\begin{array}{l}\text { - I understand } \\
\text { - I don't understand } \\
\text { - I have some doubts }\end{array}$ & \\
\hline 4 & Exercise & $\begin{array}{l}\text { Modification of the tags of a Tag } \\
\text { Library }\end{array}$ & $\begin{array}{c}\text { Tag } \\
\text { Libraries }\end{array}$ & Application & & $\begin{array}{l}\text { - Not started } \\
\text { - In progress } \\
\text { - Finished } \\
\text { - I don't know how to do it }\end{array}$ \\
\hline 5 & Discussion & $\begin{array}{l}\text { Discussion on the benefits and } \\
\text { limitations of the tag libraries }\end{array}$ & $\begin{array}{l}\text { Tag } \\
\text { Libraries }\end{array}$ & Comprehension & & $\begin{array}{l}\text { - Nothing to say } \\
\text { - I can comment if you ask } \\
\text { me } \\
\text { - I'll like to give my } \\
\text { opinion }\end{array}$ \\
\hline
\end{tabular}




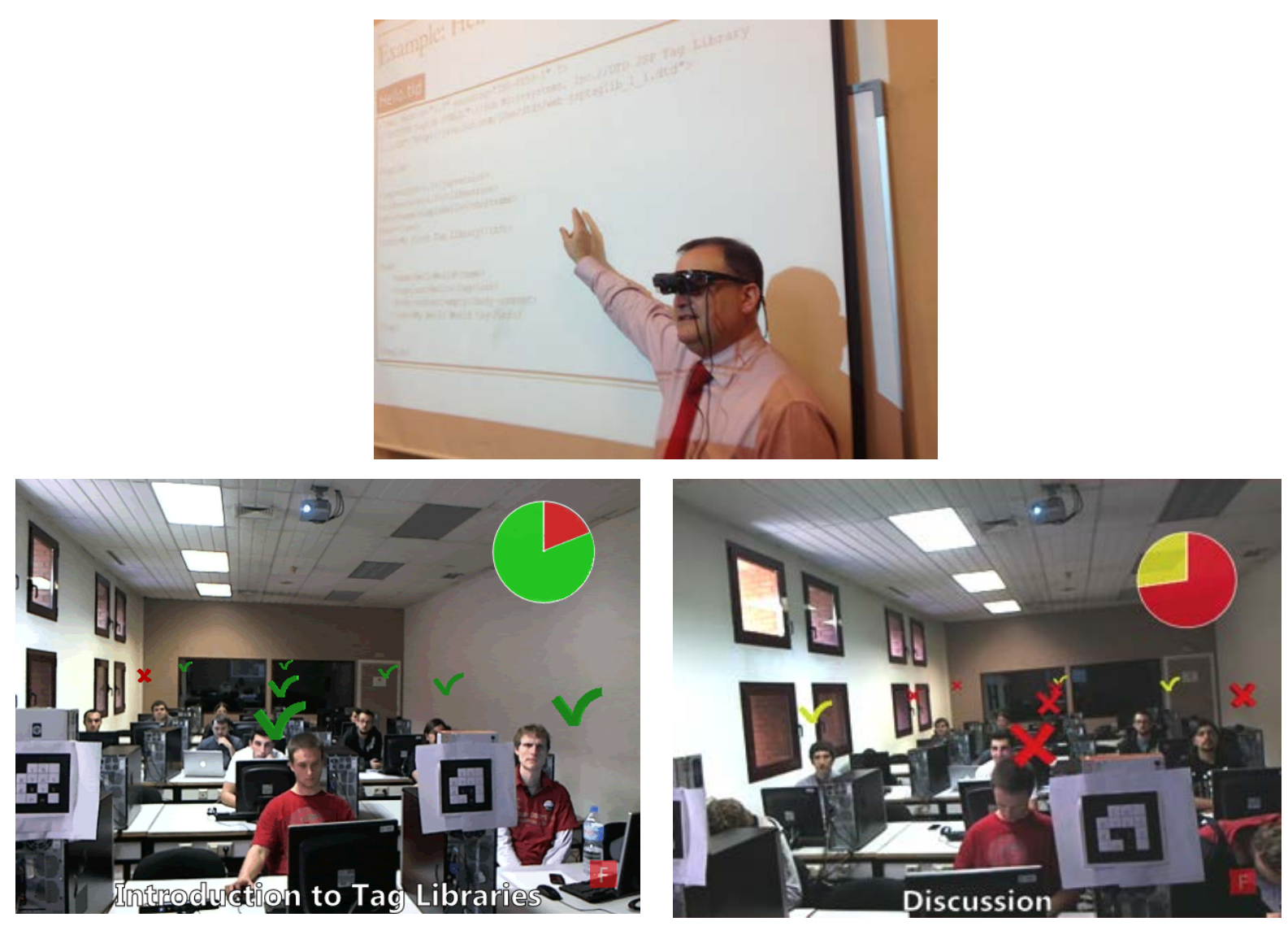

Fig 5: Pictures taken during the augmented lecture 
Table 2: Survey used for evaluating students experience, and median and standard deviation of the answers collected

\begin{tabular}{|c|c|c|c|}
\hline \multicolumn{2}{|r|}{$\begin{array}{l}\text { Section 1. Your responses to the following questions should reflect your overall experience during the lecture. } \\
\text { ( } 1=\text { strongly disagree, } 2=\text { disagree, } 3=\text { indifferent, } 4=\text { agree, } 5=\text { strongly agree) }\end{array}$} & \multicolumn{2}{|c|}{ ANSWERS } \\
\hline & Questions & $\mu$ & $\bar{\sigma}$ \\
\hline Q1 & $\begin{array}{l}\text { In general, I felt less reluctant to communicate my status and knowledge state to the teacher than in } \\
\text { a normal lecture. }\end{array}$ & 3,55 & 1,18 \\
\hline Q2 & $\begin{array}{l}\text { I think that the system could help to improve the communication between students and the } \\
\text { lecturer. }\end{array}$ & 3,82 & 0,70 \\
\hline Q3 & I think that the system could help to improve the interaction between students and the lecturer & 4,00 & 0,85 \\
\hline Q4 & $\begin{array}{l}\text { Always having to communicate my status to the lecturer made me feel more engaged with the } \\
\text { activities of the lecture. }\end{array}$ & 4,00 & 1,13 \\
\hline Q5 & I don't like the idea that the lecturer is aware of my knowledge state all the time. & 2,27 & 1,56 \\
\hline Q6 & If I were offered the possibility of using a similar system in the future, I would use it. & 3,45 & 1,21 \\
\hline \multicolumn{2}{|r|}{$\begin{array}{l}\text { Section 2. Considering your own experience during the lecture, please rate how useful you think the system is } \\
\text { when used to support communication with the teacher in each of the following lecture activities } \\
\text { ( } 1=\text { not useful at all, } 2=\text { not useful, } 3=\text { indifferent, } 4=\text { useful, } 5=\text { very useful) }\end{array}$} & \multicolumn{2}{|c|}{ ANSWERS } \\
\hline \multicolumn{2}{|r|}{ Lecture Activities } & $\mu$ & $\boldsymbol{\sigma}$ \\
\hline Q7 & Question rounds & 4,36 & 1,18 \\
\hline Q8 & Teacher explanations & 3,64 & 1,30 \\
\hline Q9 & Exercises & 3,55 & 1,35 \\
\hline Q10 & Discussions & 3,18 & 1,25 \\
\hline \multicolumn{2}{|c|}{ Section 3. Please answer the following questions. } & & \\
\hline Q12 & e would like to know any additional comments or suggestions you may have. & & \\
\hline Q13 & What is your overall opinion on the system? & & \\
\hline
\end{tabular}



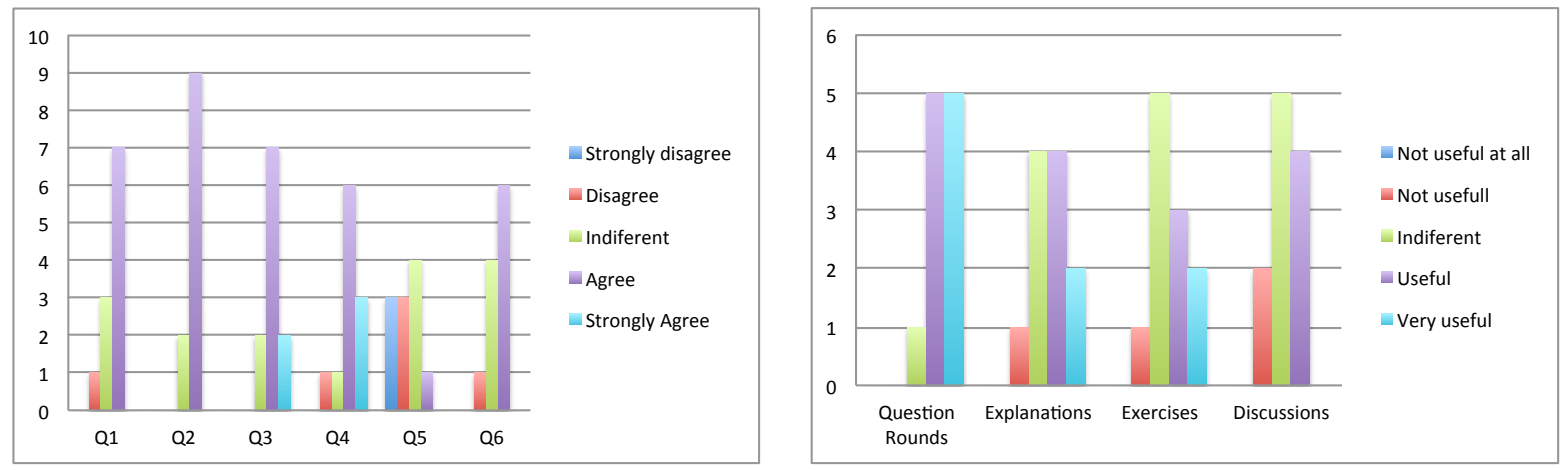

Figure 6: Distribution of the answers to section 1 and section 2 